\title{
Right Lung Bronchiole
}

National Cancer Institute

\section{Source}

National Cancer Institute. Right Lung Bronchiole. NCI Thesaurus. Code C49279.

A bronchiole located in the right lung. 